\title{
Revising and Metadiscourse in Advanced EFL/ESL Writing
}

\author{
Urška Sešek \\ Department of English, Faculty of Arts, University of Ljubljana, Slovenia \\ Aškerčeva 2, 1000 Ljubljana, Slovenia \\ E-mail: urska.sesek@ff.uni-lj.si
}

Received: 10-11-2015

Published: 01-05-2016
Accepted: 28-01-2016

doi:10.7575/aiac.ijalel.v.5n.3p.35
Advance Access Published: March 2016

URL: http://dx.doi.org/10.7575/aiac.ijalel.v.5n.3p.35

\begin{abstract}
The study explores the interplay of EFL/ESL writers' composing processes and features of their written products, specifically revising and use of metadiscourse elements. Both are crucial to success in writing but have so far not been researched from this perspective. A corpus of 104 essays, draft versions and corresponding final versions written by 52 advanced EFL/ESL writers, was analysed manually and electronically to show the use of metadiscourse elements and the revisions made in the process of writing. The two sets of data were then analysed statistically to uncover potential correlations. While there was variation in the quantities of both metadiscourse elements and text revisions, patterns emerged in both areas. Increased density of metadiscourse correlated positively with the number of major content revisions, but not with the number of minor content revisions and surface revisions. Content analysis found that metadiscourse elements were often integral parts of added chunks of text, but also served to modify or restructure existing text. Results suggest that while metadiscourse depends on genre and topic, it also plays a significant role in the process of text composing. The growth of its density as writers revise texts at the level of content and structure indicates that metadiscourse can function as a reconceptualizing tool in the process of writing.
\end{abstract}

Keywords: EFL/ESL writing, metadiscourse, revising, content revisions, surface revisions, correlations

\section{Introduction}

Over the past decades, there has been considerable investigation into both the process and product aspects of ESL/EFL writing. As far as the process is concerned, it is now widely accepted that '[...] more skilled second-language writers

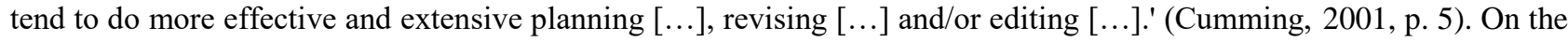
product side, while there cannot be any universal model of a 'good text', ESL/EFL writing has been researched extensively at all levels, from syntax and lexis to culture and genre (see Hinkel, 2011, for a review). Due to the complexity of both process and product, however, much research has dealt with them in relatively separate terms (Cumming, 2001, p. 2) despite the fact that they are strongly interrelated. As a result, knowledge of these relations tends to be patchy, and ESL/EFL writing pedagogy could benefit from more insight into the interplay between composing processes and features of text product (Ortega, 2009, p. 238; Pennington \& So, 1993, p. 45).

The issue can be approached from two ends. Van Wijk \& Sanders (1999), for example, took the product as their point of departure and investigated the extent to which we can reconstruct the writer's composing strategies from the features of the finished text. However, from the point of view of teaching EFL /ESL writing, it is more interesting to ask how different composing strategies lead to a certain quality of the resulting text.

Research into these questions is not abundant, and has mostly juxtaposed one chosen aspect of the composing process with one or a few aspects of text product. For example, Torrance \& Bouayad-Agha (2001) and Johnson, Mercado \& Acevedo (2012) explore the effect of planning on various text features, and Stevenson, Schoonen \& de Glooper (2006) look at the effect of revision frequency on text quality. A broader scope of factors is dealt with by Pennington and So (1993) and Sasaki (2000). In the present study, we explore the relationship between two key aspects of writing process and product which have so far not been juxtaposed: revising as an aspect of the composing process and metadiscourse elements as an aspect of text product.

The importance of revising has been acknowledged since the early explorations of writing processes (Flower \& Hayes, 1980), but it has mostly been researched in terms of the type of revisions and their cognitive background. L2 writers tend to revise more than L1 writers (Chenoweth \& Hayes, 2001), and their revisions seem to be more at the surface linguistic level (New, 1999; Thorson, 2000). Stevenson et al. (2006) explore 'the inhibition hypothesis' that because in L2 writing more cognitive resources are needed for processing language per se, this may be detrimental to other aspects of the process such as in-depth revising. Recent studies mostly explore techniques and tools for enhancing L2 writers' use of revisions (Lee \& Schallert, 2008; Min, 2006; Williams, 2004). Few studies in ESL/EFL writing, however, have looked at revising from the perspective of the process-product comparison.

The text characteristics which have so far been studied in conjunction with writing process include grammar, lexis, fluency and overall text quality, but not the building blocks of rhetorical structure and textual interaction - 
metadiscourse. In recent decades, metadiscourse has been recognized as a key component of text and has been the focus of numerous studies (e.g. Abdi, Rizi \& Tavakoli, 2010; Ädel, 2006; Crawford Camiciottoli, 2003; Crismore \& Farnsworth, 1990; Hyland \& Tse, 2004; Intaraprawat \& Steffensen, 1995; Vande Kopple, 1985). There is considerable variation in the precise definitions and theoretical models of metadiscourse used in these studies (cf. Ädel, 2006, pp.157-180; Hyland, 2005, pp. 16-36). The present study uses Hyland's (2005) model, according to which metadiscourse is "the cover term for the self-reflective expressions used to negotiate interactional meanings in a text, assisting the writer (or speaker) to express a viewpoint and engage with readers as members of a particular community" (Hyland, 2005, p. 37). The model implies that all metadiscourse is used in an interpersonal function as "/by/ making references to the text, the audience or the message, the writer indicates his or her sensitivity to the context of the discourse, by making predictions about what the audience is likely to know and how it is likely to respond." (Hyland, 2005, p.45). Hyland's functional classification of metadiscourse consists of two main categories with five subcategories each. Interactive elements are those which reflect the author's awareness of the audience in text structuring, while interactional elements reflect the writer's perspective towards the content and the readers.

Another reason for studying the relationship between revising and metadiscourse - in addition to the importance of both in their own right and lack of such studies so far - is that they seem to be linked to a common denominator. Metadiscourse is definitely related to the writer's audience awareness (c.f. Hyland, 2005), and some research has suggested that audience awareness is a major factor in effective revising (Hadis, 2010; Sato \& Matsushima, 2006; Zainuddin \& Moore, 2003). If revising and metadiscourse are at least partly motivated from the same source, we can hypothesize a correlation between the two.

Thus, the main research question of this study was: What is the relationship between revisions in the process of writing and the use of metadiscourse at different stages of this process?

The specific research questions were as follows:

1. What types of metadiscourse were used in the draft / final product and what was their frequency?

2. What types of revisions were made in the process of writing and what was their frequency?

3. What is the relationship between the revisions overall and the changes to the metadiscourse?

It has to be noted here that we assumed the amount and type of metadiscourse and revisions to be at least somewhat indicative of their overall appropriateness/effectiveness as an aspect of text quality. Text quality has namely been suggested to correlate positively to both rich and effective use of metadiscourse (Gold Sanford, 2012; Intaraprawat \& Steffenson, 1995) and rich and effective use of revising (Cumming, 2001, p.5; Stevenson et al. 2006, pp. 204, 205; Zainuddin \& Moore, 2003). Another consideration was that our participants were EFL writers. While the writer's language proficiency certainly plays a role, research suggests that the quality of L2 text is more strongly related to the quality of the writer's process than their L2 proficiency (Whalen \& Menard, 1995). In addition, the participants in our study were advanced EFL learners with a relatively high level of L2 proficiency as well as 'rhetorical acculturation' (Reid, 1984, p. 149).

\section{Method}

The study was carried out at the University of Ljubljana, Slovenia, as an experiment in which 60 students majoring in English as a foreign language produced one essay for the purpose of the study, submitting both a draft and the final version, and these were subsequently analysed for the use of metadiscourse and the revisions each writer made in the process. The data on these two variables was then analysed statistically to find potential correlations.

It has to be noted here that while for decades Slovenia has been an EFL setting, the current generations of English learners, particularly those who choose English as a university major like the participants in our study, are exposed to greatly increased amounts of different types of discourse in English. This is due to various economic and political factors and is so prominent that we believe the distinctions between EFL and ESL are becoming less relevant, and findings about the learning and use of English in Slovenia can be extended to ESL contexts.

\subsection{Data collection}

The participants were asked to write an expository essay of 600 - 800 words. They were required to submit a draft in one week's time, and the final version after another week. The study was designed so as to get as much data as possible from a single instance of the essay-writing process, and thus setting strict deadlines for the submission of both a draft and the final version was a key feature. While language teachers in Slovenia often do not require students to draft their writing, this procedure ensured that all participants' process had at least two phases and produced two sets of output that allowed for comparative analysis. Those students who failed to produce drafts, turned in outlines instead of drafts, or whose drafts were identical to the final versions were struck from the sample, which led to a final collection of 104 pieces of writing (two sets of 52).

Apart from requiring submission of two versions of the essay, we tried to approximate the usual input and constraints of the participants' essay writing experience for better reliability of the results. No feedback on the content, structure and linguistic accuracy of the draft was given. The students were encouraged as a group to revise and develop the essay, but we avoided suggesting the exact type or scope of revisions as well as individual feedback in order to capture the writers' independent text-composing process. Special care was given to the selection of the prompt, topic and type of essay required. The participants are used to prompts in the form of titles, usually on general topics and geared towards expository and argumentative writing. We wanted to avoid them having to do research for their essays because there is 
not much stress on research writing in Slovenia, particularly not in FL classes. The prompt had to be straightforward, to minimize students' frustration in interpreting it, but at the same time sufficiently open-ended. After a careful consideration of these criteria, the title was chosen to be 'Student life is different'.

Both versions of the essay written by each student were submitted in electronic form so as to enable a maximally objective procedure of recording the revisions made between the two versions, a document comparison using the relevant Microsoft Word function.

\subsection{Data analysis}

The first phase after data collection was a manual pilot analysis of 5 essays, which was conducted in order to fine-tune the procedure and appropriateness of the coding categories before analyzing the entire corpus. The next stage was the coding of all research data (104 texts), carried out separately for the two types of data: the metadiscourse used in the essays and the revisions made by the writers. The metadiscourse was coded electronically first and then checked manually, while text revisions are too complex a textual phenomenon and had to be coded manually only. In the final phase, the two sets of data were re-analysed in conjunction: for each essay, the draft and the final version, coded for metadiscourse and merged to show the revisions, were printed out and reviewed manually.

\subsubsection{The writers' use of metadiscourse}

To obtain data on the writers' use of metadiscourse, an electronic analysis of the corpus of essays was carried out using a list of search items compiled based on Hyland's (2005, pp. 218-224) list of metadiscourse items. Of course, the list had to be modified as it was based on a corpus of journal articles while the corpus in our study comprised student essays. While these two text types certainly overlap to some extent, we adapted Hyland's list in two steps. First, we identified and struck from it those items which obviously would not appear in two-page student opinion essays. Below we provide a sample from the list of items that we used, showing representatives of the two types of metadiscourse; interactional and interactive (Table 1).

Table 1. Sample lists of metadiscourse items used in the analysis

Sample interactive metadiscourse: Sample interactional metadiscourse: attitude markers
frame markers for sequencing

Hyland's list: (in) chapter $\mathrm{X}$, (in) part $\mathrm{X}$, (in) section $\mathrm{X}$, (in) the $\mathrm{X}$ chapter, (in) the $X$ part, (in) the $X$ section, (in) this chapter, (in) this part, (in) this section, finally, first, first of all, firstly, last, lastly, listing (a, b. c, etc.), next, numbering (1. 2, 3, etc.), second, secondly, subsequently, then, third, thirdly, to begin, to start with
Hyland's list:admittedly, agree, agrees, agreed, amazed, amazing, amazingly, appropriate, appropriately, astonished, astonishing, astonishingly, correctly, curious, curiously, desirable, desirably, disappointed, disappointing, disappointingly, disagree, disagrees, disagreed, dramatic, dramatically, essential, essentially, even x, expected, expectedly, fortunate, fortunately, hopeful, hopefully, important, importantly, inappropriate, inappropriately, interesting, interestingly, prefer, preferable, preferably, preferred, remarkable, remarkably, shocked, shocking, shockingly, striking, strikingly, surprised, surprising, surprisingly, unbelievable, unbelievably, understandable, understandably, unexpected, unexpectedly, unfortunate, unfortunately, unusual, unusually, usual
Adapted list: finally, first, firstly, last, lastly, next, second, secondly, subsequently, then, third, thirdly, begin, start

Adapted list:admittedly, agree, agrees, agreed, amazed, amazing,
amazingly, appropriate, appropriately, astonished, astonishing,
astonishingly, correctly, curious, curiously, desirable, desirably,
disappointed, disappointing, disappointingly, disagree, disagrees,
disagreed, dramatic, dramatically, essential, even x, expected,
expectedly, fortunate, fortunately, hopeful, hopefully, important,
importantly, inappropriate, inappropriately, interesting, interestingly,
prefer, preferable, preferably, preferred, remarkable, remarkably,
shocked, shocking, shockingly, striking, strikingly, surprised,
surprising, surprisingly, unbelievable, unbelievably, understandable,
understandably, unexpected, unexpectedly,
unfortunately, unusual, unusually, usual

In the phase of a trial analysis of 5 randomly chosen essays, we then checked the appropriateness of the adapted list. None of the deleted items from Hyland's list appeared, and we did not find any items which should be added to his list. This was probably to be expected in view of the fact that the writers in our study wrote shorter, simpler texts and, despite being advanced English learners, were not as proficient and competent writers as the scientists in Hyland's corpus.

After this trial, all the corpus data was electronically analysed, and all instances of metadiscourse items from the list were coded following Hyland's (2005) classification, first as interactive or interactional, and then according to the subcategories (interactive items as transitions, frame markers, endophoric markers, evidentials or code glosses, and 
interactional items as hedges, boosters, attitude markers, self-mentions or engagement markers). The data obtained by the automatic corpus search was subsequently manually examined, and all the items not used in a metadiscoursive function were removed.

A manual qualitative analysis in addition to the electronic search was necessary because metadiscourse is not a formal category but is defined by its function; therefore, "there are no simple criteria for identifying metadiscourse. Not only is it an open category to which new items can be added to fit the writer's needs, but the same items can function as metadiscourse in some parts of the text and not in others" (Hyland \& Tse, 2004, p. 158). In our analysis, Hyland \& Tse's (2004) three key principles of metadiscourse were used as criteria to determine whether an item should be considered metadiscoursive: metadiscourse is non-propositional, used to express writer-reader interactions and internal to discourse.

The examples below, taken from our data, illustrate how first and second (very frequent in the corpus) can be used interpersonally as metadiscourse, to contribute to the organization of the text (Examples 1 and 2), or as part of the propositional content, to clarify the order of importance or temporal relations between activities, events or ideas (Examples 3 and 4).

\section{Example 1}

The first issue is social matters. University can be very intense and overwhelming at the beginning. Some people have trouble meeting new people, making friends, and fitting in. Others have trouble learning how to balance classes and social life at the same time. ... The second issue is an expensive life.

Example 2

Firstly, there are some major differences between high school life and student life. There is first the long expected independence which is also immediately linked to responsibility.

Example 3

What's important is keeping your priorities straight: school first, partying second.

Example 4

Whereas if you have a full time job, you cannot miss a day at work unless you call in sick first and have proof that you need a few days off.

\subsubsection{The writer's process}

The revisions made to each text were made visible through a digital comparison of each participant's draft to the corresponding final version of the essay, and then coded manually. In determining the coding categories for the analysis of the learners' revisions, we drew on the revision taxonomy provided by Stevenson et al. (2006), which distinguishes between content, linguistic and typographic revisions. We considered linguistic and typographic revisions in the same category of surface changes as opposed to changes to text content, which we further divided into minor and major. Each type will be explained and illustrated with examples from our corpus of essays, in a minimal context. The underlined parts of the excerpts are the ones which were added, deleted or modified.

Content revisions were further divided into two categories: minor and major. Major content revisions were defined as changes to meaning and structure at the level of a paragraph or the whole text, as illustrated by Examples 5 and 6.

\section{Example 5}

DRAFT: The majority of the lectures are optional, and not like in grammar school where attendance was obligatory in every subject. Here, nobody cares if you don't come. And nobody cares if you do either.

FINAL: The majority of the lectures are optional, and not like in grammar school where attendance was obligatory in every subject. In grammar school, the class also worked as a unit; everyone knew who the other was in love with, what shirt he or she wore the previous day etc. Here, everything is liberated._No one cares if you don't come to class, and no one cares if you do either.

\section{Example 6}

DRAFT: (the essay had no concluding paragraph)

FINAL: To conclude in the spirit of differences, student life is also different than the clichés about it might suggest. Yes, it is a period of possibly greatest parties ever, but contrary to popular belief it is not just excessive drinking and doing nothing all day long. I realized it is more about discovering what your real interests are, forming strong bonds with people who might accompany you throughout your whole life and at the same time acquiring a formal education which will hopefully lead to a great success in the business area of life as well.

Minor content revisions were defined as changes to meaning at the level of a phrase, clause or sentence which do not affect the structure or propositional content at the level of a paragraph or whole text, as illustrated by Examples 7, 8 and 9. 
Example 7

DRAFT: Getting a job is quite easy, but the choices are limited.

FINAL: Getting a job is quite easy, as students have an option to visit several students' employment centres, but the choices are limited.

Example 8

DRAFT: Attending several parties a week and sleeping an hour per night takes its toll.

FINAL: Attending several parties a week and only getting forty winks per night takes its toll.

Example 9

DRAFT: The first problem I had to face with was finding an apartment.

FINAL: The first problem I had to face with was finding an affordable apartment.

The third category - language revisions - included surface changes which do not affect meaning, e. g. minor lexical and grammatical modifications (accuracy, register) and typographic corrections, as illustrated by Examples 10-13.

Example 10

DRAFT: Weren't students always the population that engaged in revolutions?

FINAL: Were students not always the population that engaged in revolutions?

Example 11

DRAFT: Exams all wait until June,...

FINAL: All the exams wait until June, ...

Example 12

DRAFT: The student years are so significant, because you have a total control over your destiny.

FINAL: The student years are so significant because you have a total control over your destiny.

Example 13

DRAFT: You spend your afternoons in the city, sitting around on coffee.

FINAL: You spend your afternoons in the city, sitting around drinking coffee.

The tallied results of all the qualitative analyses - for the metadiscourse and the process part - were fed into a single spreadsheet for an overview of all the results across the variables and for individual participants. This was used for statistical processing and representation including graphs, structural tables and the Spearman correlation coefficient with the corresponding p-value.

\section{Results and discussion}

\subsection{Types and frequency of metadiscourse elements}

The total amount of metadiscourse in the finished essays was visibly larger than in the drafts, but variation was also high. While the majority of the participants increased their use of metadiscourse to different degrees, three out of 52 actually used less of it in the final version. (Note that we did not record this as negative numbers because we did not categorize revisions as deletions/additions and it was necessary to have positive values of both variables for the purpose of calculating correlations.)

Table 2. Metadiscourse use in drafts and finished essays (overall categories)

\begin{tabular}{lllll}
\hline & $\begin{array}{l}\text { Average } \\
\text { number in } \\
\text { drafts }\end{array}$ & $\begin{array}{l}\text { Average number in } \\
\text { finished essays }\end{array}$ & $\begin{array}{l}\text { Average density in } \\
\text { drafts (per 100 } \\
\text { words })\end{array}$ & $\begin{array}{l}\text { Average density in f } \\
\text { finished essays (per 1 } \\
100 \text { words) }\end{array}$ \\
\hline Total & 43.8 & 56.7 & 7.6 & 7.7 \\
& $(\mathrm{SD}=27.1)$ & $(\mathrm{SD}=33.8)$ & $(\mathrm{SD}=3.5)$ & $(\mathrm{SD}=3.0)$ \\
Interactional & 32.8 & 42.6 & 5.7 & 5.8 \\
& $(\mathrm{SD}=21.8)$ & $(\mathrm{SD}=26.8)$ & $(\mathrm{SD}=3.0)$ & $(\mathrm{SD}=2.7)$ \\
\hline Interactive & 11 & 14.1 & 1.9 & 1.9 \\
& $(\mathrm{SD}=7.7)$ & $(\mathrm{SD}=9.9)$ & $(\mathrm{SD}=0.9)$ & $(\mathrm{SD}=0.8)$ \\
\hline
\end{tabular}


In interpreting the quantity of any text element in a given body of texts, we have to consider the factor of text length. In our case, the number of MD elements was rendered quite relative by the variation in text length. The mean length of drafts was 553 words (SD 149), and the mean length of finished essays was 710 (SD 197). We therefore calculated the density of metadiscourse in each essay as the number of words representing metadiscourse per 100 words. From Table 1 we can see that, on average, metadiscourse density hardly changed in the process of writing, meaning that metadiscourse was largely added as part and parcel of adding text 'bulk'. However, if we look at the detailed data rather than averages (Figure 1, showing the change of metadiscourse density for each of the 52 individual essays), we can see that metadiscourse was also the object of revisions in its own right or even a medium for rethinking the text, as will be shown in 3.3 .

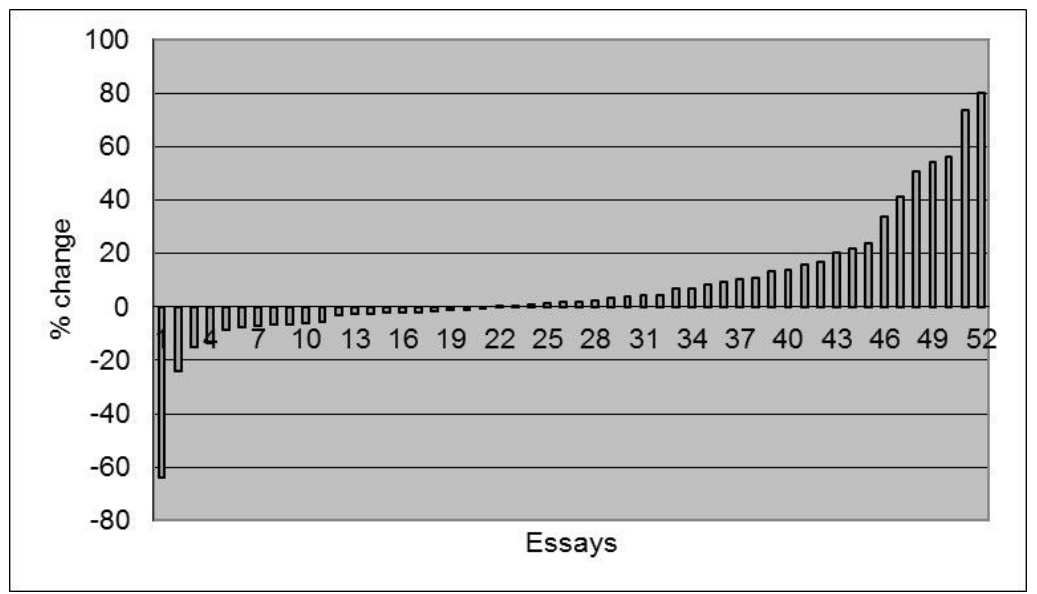

Figure 1. Increase/decrease of metadiscourse density in individual essays (percentages)

If we look beyond overall quantity at what types of metadiscourse were used at the two stages of the writing process, the first finding is that of the two main categories, interactional metadiscourse was considerably more frequent in the essays - at both stages - than interactive (as we could see already in Table 2). This is probably due to genre and topic: these enabled the writers to draw most of the content from their personal experience and did not require any research (hence, for example, few citations and code glosses, but many self-mentions). Also, the structure of the text was basically that of the 5-paragraph essay, which, being fairly short and with a highly conventionalized structure, does not need to rely heavily on interactive metadiscourse to navigate the reader.

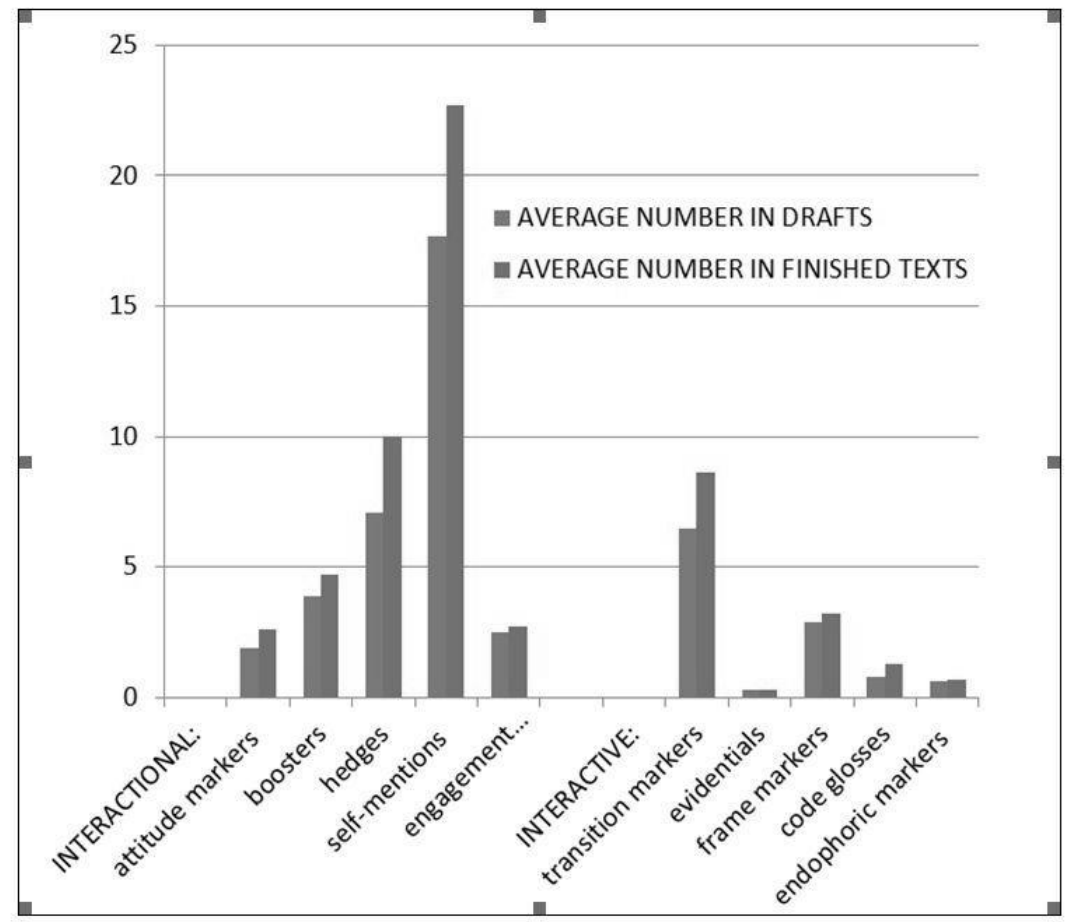

Figure 2. The use of different types of metadiscourse elements in the essays: drafts vs. final versions

As we can see in Figure 2, not only did the proportions of both types of metadiscourse between the draft stage and the finished product remain similar, so did the proportions between the individual subtypes. In the final version of the text, participants tended to add those types of items which were already present in the draft. Table 2 shows a typical 
participant's exact use of each of the 10 different types of metadiscourse items in the essay draft as compared to the final version of the text.

Table 3. Use of individual types of metadiscourse items in drafts and finished texts - sample

\begin{tabular}{|c|c|c|c|c|c|c|c|c|c|c|c|}
\hline & 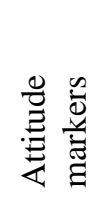 & 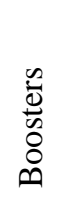 & $\begin{array}{l}0 \\
0 \\
0 \\
0 \\
0 \\
00 \\
0 \\
0 \\
0 \\
0\end{array}$ & 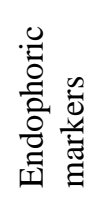 & 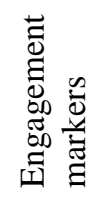 & 蔦 & 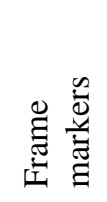 & $\begin{array}{l}\mathscr{D} \\
\stackrel{\infty}{0} \\
\mathbb{I}\end{array}$ & 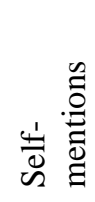 & 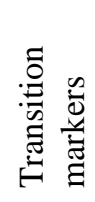 & స్తేర \\
\hline Draft6U1 & 2 & 7 & 1 & 0 & 2 & 0 & 0 & 8 & 3 & 7 & 30 \\
\hline Final6U1 & 4 & 5 & 1 & 0 & 2 & 0 & 1 & 11 & 6 & 7 & 37 \\
\hline
\end{tabular}

\subsection{Types and frequency of revisions}

Independently from measuring the use of metadiscourse elements at both stages of the essay writing, we identified the revisions the participants made to their texts in terms of content, organization and language usage. As already explained, these were defined at three levels. The average amount of recorded revisions of each type is shown in Table 4 below.

Table 4. Amount of revisions made at different levels

\begin{tabular}{cll}
\hline Type of revision & $\begin{array}{l}\text { Mean number of } \\
\text { revisions made }\end{array}$ & SD \\
\hline All revisions & 16.5 & 12.5 \\
\hline Major content changes & 2.4 & 2.6 \\
\hline Minor content changes & 3.6 & 3.4 \\
\hline Language changes & 10.5 & 11.7 \\
\hline
\end{tabular}

As with the metadiscourse found in the corpus, there was also considerable variation in the amount of revising; SD is high, particularly for the category of language revisions, which means that some participants made almost no surface changes to their evolving texts, while others made up to more than 30 . Overall, however, the participants made more surface revisions to their essays than content revisions. It is to be expected that EFL writers make quite a lot of language edits, and, by extension, probably also the ratio of major and minor content revisions is not surprising. At the same time the relatively high number of both types of content revisions combined (6, compared to 10.5 surface revisions) indicates that most participants did develop their texts at a conceptual level as well.

\subsection{Relationship between revisions and metadiscourse}

In order to get an insight into how the writers' use of metadiscourse interplayed with the process of revising, we calculated correlation coefficients between the change in the density of metadiscourse (overall, interactional and interactive) and the amount of different types of revisions made. Since the distribution of data deviated from normal and there were no particular grounds to assume that the correlation is linear, we used the Spearman's coefficient, which in comparison to the more widely used Pearson's coefficient is less sensitive to outliers and can capture non-linear correlations as well.

Table 5. The correlations of change in metadiscourse density and overall text revisions

\begin{tabular}{llll}
\hline Data set A (\%) & Data set B (no. of units) & $\begin{array}{l}\text { Spearman's } \\
\text { coefficient }\end{array}$ & p-value \\
\hline $\begin{array}{l}\text { change in the density } \\
\text { metadiscourse used }\end{array}$ & All revisions & $\rho=0.00$ & 0.94 \\
“ & Major content revisions & $\rho=0.34$ & 0.01 \\
“ & Minor content revisions & $\rho=0.09$ & 0.51 \\
\hline “ & Surface revisions & $\rho=-0.10$ & 0.44 \\
\hline
\end{tabular}

The next table shows the same calculations probing whether text revisions were related differently to the changes in interactional vs. interactive metadiscourse elements. In Table 6, we can see the same pattern of correlations for both subcategories as for the category of metadiscourse overall. 
Table 6. The correlations of changes in the density of interactional and interactive metadiscourse and overall text revisions

\begin{tabular}{|c|c|c|c|}
\hline Data set A (\%) & Data set B (no. of units) & $\begin{array}{l}\text { Spearman's } \\
\text { coefficient }\end{array}$ & $\mathrm{p}$-value \\
\hline \multicolumn{4}{|c|}{ INTERACTIONAL METADISCOURSE } \\
\hline change in the density & All revisions & $\rho=0.02$ & 0.90 \\
\hline “ & Major content revisions & $\rho=0.40$ & 0.00 \\
\hline “ & Minor content revisions & $\rho=0.12$ & 0.37 \\
\hline “ & Surface revisions & $\rho=-0.19$ & 0.16 \\
\hline \multicolumn{4}{|c|}{ INTERACTIVE METADISCOURSE } \\
\hline change in the density & All revisions & $\rho=0.06$ & 0.66 \\
\hline “ & Major content revisions & $\rho=0.35$ & 0.00 \\
\hline “ & Minor content revisions & $\rho=-0.04$ & 0.87 \\
\hline “" & Surface revisions & $\rho=-0.07$ & 0.63 \\
\hline
\end{tabular}

As Tables 5 and 6 show, there are important differences in the correlations of the changes in metadiscourse density to different types of revisions. (Note that in $60 \%$ of the cases the change means increase). The two clearly correlated variables were metadiscourse density and major content revisions. This is an interesting finding, particularly given the fact that this was the least frequent type of revisions (see 3.2.). It suggests that metadiscourse plays an important role in content revising beyond the sentence level; of course, metadiscourse is not, by definition, a surface text feature, but this finding underlines its centrality not only in the text as a product or its reception by readers but also in the process of its creation. Let us look at the interplay of metadiscourse use and major content revisions more closely with the help of examples from the data corpus.

The first set of examples shows how metadiscourse elements were often added in the phase of essay development as an integral part of added chunks of new text rather than as modification of the existing text. This is understandable since the participants were producing a conventionally structured essay on a familiar topic, and mostly did not struggle to commit to a clear thesis. Their transition from the draft to the final version mostly entailed generating enough ideas to develop the paragraphs. Thus, when writers added chunks of several sentences to an existing paragraph or even entire new paragraphs, their additions almost invariably included some metadiscourse elements, as seen in Examples 14 and 15 , in which the draft and the final version are juxtaposed (the metadiscourse elements are underlined, their coding given in brackets and the added chunk of text marked by bold print).

\section{Example 14}

DRAFT: On the other hand (tm), when looking for private accommodation, you should (eg) think carefully about who to live with. It can sometimes (hd) be easier to live with people who aren't your very closest friends; at least according to my (sm) experience.

FINAL: On the other hand (tm), when looking for private accommodation, you should (eg) think carefully about who to live with. It can sometimes (hd) be easier to live with people who aren't your very closest friends; at least according to my (sm) experience. In my (sm) opinion (hd) it was a logical option to move in with my (sm) best friend. Unfortunately (am) it turned out that being friends with someone and living with them can be very different. We (sm) were not honest with one another and did not know our ( $\mathrm{sm}$ ) rights and expectations. Fortunately (am) we (sm) figured that out soon enough and an "unpleasant experience" of living together did not affect our (sm) friendship.

Example 15

DRAFT: First (fm) you have to choose classes you want to attend and at the same time (tm) also (tm) assure some spare time for lunch. It is a big achievement if you can do that successfully. $I(\mathrm{sm})$ remember having quite some problems with my $(\mathrm{sm})$ own schedule. Another $(\mathrm{fm})$ significant distinction in comparison with high school is that tutorials are not obligatory.

FINAL: First (fm) you have to choose classes you want to attend and at the same time (tm) also (tm) assure some spare time for lunch. It is a big achievement if you can do that successfully. $I(\mathrm{sm})$ remember having quite some problems with my (sm) own schedule. We (sm) did not have to worry about that in high school. There is also (fm) another (fm) distinction. In high school you had six or more periods and then went home to study. But (tm) here at the university you have maybe (hd) fewer periods but more gaps between them. The biggest gap $I(\mathrm{sm})$ have is four hours. You can make good use of those gaps for lunch or for studying. Another $(\mathrm{fm})$ significant distinction in comparison with high school is that tutorials are not obligatory. 
However, not all metadiscourse changes coupled with major content revisions were of this type. Examples 16 and 17 illustrate how metadiscourse elements were also manipulated in their own right, as a focus of revisions which affected the content or structure of the essay beyond the semantics of a single sentence. In Example 16, the writer changed the form and position of one transition marker to improve paragraph coherence, and inserted a new one to link a supporting idea from the draft to an additional point at the same level.

\section{Example 16}

DRAFT: Partying has its down sides, though $(\mathrm{tm})$ - attending 4 parties a week and sleeping an hour per night is a regular for some, but in the long run it makes them so tired that they cannot concentrate in classes and start paying less and less attention to the world around them.

FINAL: However (tm), attending several parties a week and only getting forty winks per night takes its toll. It is a regular for some, especially during their first year away from their parents, to party their nights away. Annoyance is one of the first side effects. When one did not get enough sleep, everything bothers them. Also (tm), it soon makes them so tired that they cannot concentrate in classes.

In the next example, the writer made a complex revision to their opening of the essay (three sentences). A part of the revision was replacing a description of a scene with a general statement, which involved a considerable reduction of metadiscourse.

\section{Example 17}

DRAFT: The school bell rings, we (sm) all pack our (sm) bags and make our (sm) way for the next (fm) class? No more. Uniformity was a thing of the past.

FINAL: High School offered much comfort and uniformity. But $(\mathrm{tm})$ both of these are now a thing of the past.

Let us now look at the relationship between metadiscourse and minor content revisions; Examples 18 and 19 illustrate how a minor content change could entail an addition of a metadiscoursive device.

\section{Example 18}

DRAFT: It is not like high school, when you skipped a class and just ended up trying to imitate your parents' signature to get out of trouble. In college, however (tm), professors do not care where you were and if you had a bad day.

FINAL: It is not like high school, when you skipped a class and just ended up trying to imitate your parents' signature to get out of trouble. In college, however (tm), professors do not care where you were and if you had a bad day, therefore $(\mathrm{tm})$ no written apologies are acceptable, nor do they make any difference.

\section{Example 19}

DRAFT: Job helps pay for accommodation, books, food, clothes... some people get scholarships or support from their parents, but most still take an extra job with less working hours so they can afford more comfort or some vacation in between the exam periods.

FINAL: The job helps pay for accommodation, books, food, clothes ... some people also get scholarships or financial support from their parents, but most still take at least a part time job so that they are able to afford more comfort or perhaps (hd) a short vacation in between the exam periods.

While examples of this type did occur in our corpus, statistical analysis shows that unlike major content revisions, minor revisions are not correlated with the increase in metadiscourse density in any category. This suggests that metadiscourse does not play a significant role in the semantic revising of a text below the sentence level.

The third type of revisions whose correlations with the changes to metadiscourse we examined in our study was surface revisions. It has to be noted here that while content revisions were changes to chunks as large as or larger than metadiscourse elements themselves (i. e. above the level of sentence elements or grammatical / lexical phrases), surface revisions by definition could not affect the type or amount of metadiscourse elements but only their form. In our study, even this would not be captured in the correlation statistics since the coding of metadiscourse did not record changes such as 'Furthermore,' being replaced by 'In addition,' (semantically, these are the same type of element) or typographic revisions such as 'Actualy' being corrected to 'Actually,..' '. It might thus seem that it was impossible for any correlation to show between surface revisions and changes to metadiscourse. However, since surface changes included changes to many other language elements, not just metadiscourse, it might be assumed that writers who make fewer surface changes overall attend to meaning more than to form and will also change their use of metadiscourse more. Conversely - and in accordance with the inhibition hypothesis proposed by Stevenson et al (2006) - those writers who attend to form heavily, might not be able to process their text deeply enough for the revisions to affect the 
metadiscourse level. In short, there might be a negative correlation between surface revisions and increase in metadiscourse density. The data, however, does not support this. Attention to surface text features apparently neither inhibits nor encourages a writer's thinking about metadiscourse, and the amount of surface revising is not a relevant measure of the depth of text processing in comparison to content revisions, which, as we have seen, are the ones which tend to involve metadiscourse.

\section{Discussion}

In our study, we tried to shed light on the relationship between the writing process of EFL/ESL writers and the resulting text by juxtaposing their revising and their use of metadiscourse. Of course, this relationship is a complex one; the study was limited to a quantitative perspective on the two variables, but its design allowed us to deal with them in a parallel manner so as not to unduly foreground one or the other. Despite considerable variation, there were visible overall patterns in the use of metadiscourse in the corpus, particularly in terms of the ratio between interactional and interactive elements, which was due to the constraints of the genre and topic. There was also noticeable variation in the patterns of revisions, but overall, surface revisions were more common than content revisions (as is expected in EFL/ESL writers).

In analysing for the correlations between the two phenomena, we used the density of metadiscourse rather than its absolute amount so as to acknowledge the variable of text length. Quantitative changes to metadiscourse density (mostly in the form of increase) clearly correlated positively with the amount of major content revisions, defined as revisions of the propositional content and text structure beyond sentence level. Minor content revisions did not correlate with changes in metadiscourse density. With both minor and major content revisions, metadiscourse elements were usually part and parcel of inserted sentences or paragraphs, and to some extent also independent additions which served to modify or restructure existing parts of texts. Surface revisions did not correlate with the changes to any category of metadiscourse.

All the results taken together suggest that the more writers reconceptualise the text in the process of writing, the more their use of metadiscourse changes quantitatively in the process. When writers expand by adding new chunks of text, it of course grows in absolute terms, but when they re-vision, reformulate and restructure existing text, metadiscourse also grows in density. The fact that this happens spontaneously even in EFL/EFL writers suggests that metadiscourse is not just a text feature but also an aid in composing processes, 'a writing tool' (Aitchison, 2014).

What are the potential pedagogical implications? If reconceptualising text and increased use of metadiscourse are strongly intertwined, encouraging either one or the other in the process of teaching EFL /ESL writing will lead to beneficial results. Encouraging conscious attention to metadiscourse (while this may not lead to text improvement in terms of surface features) will likely involve revisions to the content and organization of text at all levels. This finding supports the positive results of studies of explicit metadiscourse instruction using a process approach to writing (Khoshkholgh \& Akef, 2014, Cheng \& Steffensen, 2014). Our study, however, also implies that writing teachers can encourage increased use of metadiscourse (usually leading to increased text quality) by encouraging in-depth revising. Of course, combining both, as suggested by Tavakoli, Bahrami \& Amirian, 2012 (the only available comparable study to date), would probably yield best results. Examples such as provided in our study could be used to illustrate to students both different levels of revising and the role of metadiscourse in written text.

In conclusion, while it was clear at the outset that there is a relationship between revising and use of metadiscourse, we hope to have shed light on some of the complexity of this relationship. There are several questions that could be answered by further research. One such question, which would require more direct insight into the writers' thought processes, is whether content revising is more driven by propositions or by 'thinking metadiscourse'. The relationship between metadiscourse and revising could be additionally explored from the perspective of the effectiveness / appropriateness of metadiscourse use and the efficiency of revising. And, of course, to explain the nature of the link between the two aspects of writing, it would also be worthwhile to include some direct measure of audience awareness. In this way we could further increase our understanding of the role metadiscourse and revising play in the composing processes and written products, the improvement of which is the ultimate goal of ESL/EFL writing instruction.

\section{References}

Abdi, R., Rizi, M. T., \& Tavakoli, M. (2010). The cooperative principle in discourse communities and genres: a framework for the use of metadiscourse. Journal of Pragmatics, 42, 1669-1679. http://dx.doi.org/10.1016/j.pragma.2009.11.001

Ädel, A. (2006). Metadiscourse in L1 and L2 English. Amsterdam: John Benjamins. http://dx.doi.org/10.1075/scl.24

Aitchison, C. (2014). Where's this going!? Metadiscourse for readers and writers. https://doctoralwriting.wordpress.com/2014/11/15/wheres-this-going-metadiscourse-for-readers-and-writers/

Cheng, X., Steffensen, M. (2012). Metadiscourse: A Technique for Improving Student Writing. Research in the Teaching of English, 30/2, 149-181.

Chenoweth, N.A., \& Hayes, J.R. (2001). Fluency in writing: generating text in L1 and L2. Written Communication, 18, 80-98. http://dx.doi.org/10.1177/0741088301018001004

Crawford Camiciottoli, B. (2003). Metadiscourse in ESP reading comprehension: an exploratory study. Reading in a Foreign Language, 15, 1-19.

Crismore, A., \& Farnsworth, R. (1990). Metadiscourse in popular and professional science discourse. In W. Nash (Ed.), The Writing Scholar (pp. 118-136). Newbury Park, CA: Sage. 
Cumming, A. (2001). Learning to write in a second language: two decades of research. International Journal of English Studies, 1, 1-23. http://dx.doi.org/10.6018/ijes.1.2.48331

Flower, L., \& Hayes, J. R. (1980). The dynamics of composing: making plans and juggling constraints. In L. Gregg \& E. Steinberg (Eds.), Cognitive processes in writing (pp. 31-50). Hillsdale, NJ: Lawrence Erlbaum. http://dx.doi.org/10.1016/j.cedpsych.2014.11.004

Gold Sanford, S. (2012). A Comparison of Metadiscourse Markers and Writing Quality in Adolescent Written Narratives. University of Montana Scholar Works: Theses, Dissertations, Papers (Paper 1336). http://scholarworks.umt.edu/cgi/viewcontent.cgi?article=2385\&context=etd

Hadis, P. (2010). Effects of Content and Audience Awareness Goals for Revision on EFL Learners' Writing Performance. Master's thesis. University of Putra, Malaysia. http://psasir.upm.edu.my/19557/

Hinkel, E. (2011). What research on second language writing tells us and what it doesn't. In E. Hinkel (Ed.), Handbook of Research in Second Language Teaching and Learning Volume 2 (pp 523-538). New York: Routledge.

Hyland, K., \& Tse, P. (2004). Metadiscourse in academic writing: a reappraisal. Applied Linguistics, 25, $156-177$. http://dx.doi.org/10.1093/applin/25.2.156

Hyland, K. (2005). Metadiscourse. London and New York: Continuum.

Intaraprawat, P., \& Steffensen, M. S. (1995). The use of metadiscourse in good and poor ESL essays. Journal of Second Language Writing, 4, 253-272. http://dx.doi.org/10.1016/1060-3743(95)90012-8

Johnson, M. D., Mercado, L. \& Acevedo, A. (2012). The effect of planning sub-processes on L2 writing fluency, grammatical complexity, and lexical complexity. Journal of Second Language Writing, 21, $264-282$. http://dx.doi.org/10.1016/j.jslw.2012.05.011

Khoshkholgh, S., Akef, K. (2014). The Role of Process Writing in Meta-discourse Markers. LAP (Lambert Academic Publishing).

Lee, G., \& Schallert, D. (2008). Meeting in the margins: effects of the teacher-student relationship on revision processes of EFL college students taking a composition course. Journal of Second Language Writing, 17, $165-182$. http://dx.doi.org/10.1016/j.jslw.2007.11.002

Mauranen, A. (1993). Cultural Differences in Academic Rhetoric. Bern: Peter Lang.

Min, H. (2006). The effects of trained peer review on EFL students' revision types and writing quality. Journal of Second Language Writing, 15, 118-141. http://dx.doi.org/10.1016/j.jslw.2006.01.003

New, E. (1999). Computer-aided writing in French as a foreign language: a qualitative and quantitative look at the process of revision. The Modern Language Journal, 83, 81-97. http://dx.doi.org/10.1111/0026-7902.00007

Ortega, L. (2009). Studying writing across EFL contexts: looking back and moving forward. In R. M. Manchón (Ed.), Writing in foreign language contexts: Learning, teaching, and research (pp. 232-255). Clevedon, UK: Multilingual Matters. http://dx.doi.org/10.2307/41262359

Pennington, M.C., \& So, S. (1993). Comparing writing process and product across two languages: a study of 6 Singaporean university student writers. Journal of Second Language Writing, 2, 41-63. http://dx.doi.org/10.1016/10603743(93)90005-N

Reid, J. (1984). Comments on Vivian Zamel's "The Composing Processes of Advanced ESL Students: Six Case Studies”. TESOL Quarterly, 18, 149-153. http://dx.doi.org/10.2307/3586344

Sasaki, M. (2000). Toward an empirical model of EFL writing processes. Journal of Second Language Writing, 9, 259292. http://dx.doi.org/10.1016/S1060-3743(00)00028-X

Sato, K. \& Matsushima, K. (2006). Effects of audience awareness on procedural text writing. Psychological reports, 99(1), 51-73. http://dx.doi.org/10.2466/PR0.99.5.51-73

Stevenson, M., Schoonen, R., \& de Glopper, K. (2006). Revising in two languages: a multi-dimensional comparison of online writing revisions in L1 and FL. Journal of Second Language Writing, 15, $201-233$. http://dx.doi.org/10.1016/j.jslw.2006.06.002

Tavakoli, M., Bahrami, L., Amirian, Z. (2012). Improvement of Metadiscourse Use among Iranian EFL Learners through a Process- based Writing Course. Journal of English Language Teaching and Learning 9, 130-162.

Thorson, H. (2000). Using the computer to compare foreign and native language writing process: a statistical and case study approach. The Modern Language Journal, 84, 155-170. http://dx.doi.org/10.1111/0026-7902.00059

Torrance, M., \& Bouayad-Agha, N. (2001). Rhetorical structure analysis as a method for understanding writing processes. In L. Degand, Y. Bestgen, W. Spooren \& L. vanWaes (Eds.), Multidisciplinary Approaches to Discourse. Amsterdam: Nodus.

Van Wijk, C., \& Sanders, T. (1999). Identifying writing strategies through text analysis. Written Communication, 16, 51-75. http://dx.doi.org/10.1177/0741088399016001003

Vande Kopple, W. J. (1985). Some exploratory discourse on metadiscourse. College Composition and Communication, 36, 82-94. http://dx.doi.org/10.2307/357609

Whalen, K., \& Menard, N. (1995). L1 and L2 writers' strategic and linguistic knowledge: a model of multiple-level discourse processing. Language Learning,45, 381-418. http://dx.doi.org/10.1111/j.1467-1770.1995.tb00447.x

Williams, J. (2004). Tutoring and revision: second language writers in the writing center. Journal of Second Language Writing, 13, 173-201. http://dx.doi.org/10.1016/j.jslw.2004.04.009

Zainuddin, H., \& Moore, R. A. (2003). Audience awareness in L1 and L2 composing of bilingual writers. TESL-EJ, 7, 1-19. 